\title{
AGÊNCIA E REDES MUNDOS PEQUENOS: UMA ANÁLISE MULTINÍVEL DA PRODUTIVIDADE ACADÊMICA
}

LUCIANO ROSSONI

Doutor em Administração pelo Departamento de Administração da Universidade Federal do Paraná (UFPR).

Professor do Departamento de Administração da Universidade do Grande Rio (Unigranrio).

Rua da Lapa, 86, $9^{\circ}$ andar, Lapa, Rio de Janeiro - RJ - Brasil - CEP 22220-040

E-mail: Irossoni@gmail.com

Este artigo pode ser copiado, distribuído, exibido, transmitido ou adaptado desde que citados, de forma clara e explícita, o nome da revista, a edição, o ano, e as páginas nas quais o artigo foi publicado originalmente, mas sem sugerir que a RAM endosse a reutilização do artigo. Esse termo de licenciamento deve ser explicitado para os casos de reutilização ou distribuição para terceiros. Não é permitido o uso para fins comerciais. 


\section{RESUMO}

Neste artigo, objetivamos avaliar empiricamente a capacidade da agência dos pesquisadores do campo da pesquisa em organizações e estratégia no Brasil quando imersos em redes mundos pequenos (small worlds). Para tanto, assumimos que a agência pode ser avaliada quanto a seu efeito na produtividade. Depois, advogamos que tal agência pode ser explicada pela imersão em redes de coautoria, em que tanto o posicionamento privilegiado dos pesquisadores em relação às lacunas estruturais quanto a configuração de facções da rede sob a forma de mundos pequenos podem afetar a produtividade. A análise de como a estrutura social influencia o comportamento e a performance dos indivíduos é primordialmente fundamentada em estudos de análises de redes sociais. Mesmo se reconhecendo as limitações, ela é frutífera e coerente enquanto arcabouço metodológico. Contudo, paralelamente, modelos estatísticos multiníveis vêm sendo empregados. Comumente conhecidos como modelos lineares hierárquicos, ou modelos HLM, eles buscam avaliar como o contexto interfere na ação social. Diante dessas duas possibilidades, buscamos neste estudo conciliar a análise de redes com modelos hierárquicos para avaliar a agência como socialmente imersa em redes de relações. Para tanto, o campo científico é tomado como um tipo de sistema social, cujas redes de relações de coautoria são avaliadas como dimensão estrutural quanto a posição-prática. Isso porque há indícios de que a estrutura de relacionamento interfira tanto no processo de institucionalização das ações, quanto na capacidade de agência dos pesquisadores. Verificamos que pesquisadores com maior proporção de laços não redundantes são mais produtivos. Além disso, as análises apontaram que em redes mais coesas a respeito de mundos pequenos, tanto individual quanto coletivamente, a produtividade é maior. Todavia, quando essa coesão é muito alta, há tendência de a produtividade decair. Tais resultados apontam para a relevância de se avaliar a capacidade da agência quando imersa em redes de relações, já que diferentes mecanismos de capital social condicionam a ação e seus resultados. 


\section{PALAVRAS-CHAVE}

Agência. Estrutura. Redes mundos pequenos. Buracos estruturais. Produtividade acadêmica.

\section{INTRODUÇÃO}

A compreensão do resultado das ações de agentes humanos e organizacionais recai hora na primazia do indivíduo, hora na do coletivo. Assim, fenômenos sociais tendem a ser explicados a partir de uma única lógica, contrapondo agência e estrutura. Basicamente isso ocorre porque o significado de agência está atrelado à liberdade, e o de estrutura, à coerção (Giddens, I978). Tal posicionamento vem sendo confrontado cada vez mais, já que a ideia de recursividade entre agência e estrutura vem ganhando espaço nas discussões acadêmicas (Reed, 2003). Aceitar a recursividade entre agência e estrutura significa dizer que o foco da experiência humana recai sobre as práticas sociais (Giddens, I989). Dessa forma, estruturas existem e persistem essencialmente porque compõem a ação, pois são postas em uso em contextos de interação. Nesse caso, estruturas são virtuais, presentes como traços de memória, e existem somente porque são reproduzidas (Giddens, I989). Tal definição leva a aceitar que só há estrutura se houver ação, e, perante a ação, estruturas são constituídas e reconstituídas num processo de contínua estruturação: elas tanto antecedem a ação como conjunto de regras e roteiros, quanto são resultado de processos sucessivos de interação.

Nessa linha de argumentação, estruturas são vistas como padrões, condicionando o leque de possibilidades de nossas escolhas diante de situações específicas. Pelo contrário, sem tais padrões de conduta, não haveria escolhas a tomar, pois qualquer racionalização da ação sempre ocorre dentro de parâmetros de referência que, se postos de lado, impossibilitariam qualquer apreensão e interpretação da realidade. Assim, estruturas institucionais não apenas condicionam a ação, mas também a habilitam - tendo caráter dual, atuando como canalizadores e até estimuladores da ação.

Diante da dualidade da estrutura (Giddens, I978, I989), seria um equívoco pensar que o oposto da ausência de padrões estruturados de ação seja a completa liberdade: indivíduos precisam de parâmetros para pensar e criar. Com efeito, aceitar a ideia de agência como o fator criativo e facilitador (Emirbayer \& Mische, I998) não significa dizer que o indivíduo como agente é um ser não socializado, mas só é agente à medida que estiver imerso em sistemas sociais. Portanto, agência é equiparada à incorporação das estruturas sociais sob uma unidade peculiar, por exemplo, o corpo, cuja ação reconstrói esses padrões. 
Sob essa lógica, pode-se buscar compreender a capacidade da agência humana a partir dos resultados da ação dos indivíduos enquanto agentes, cujo efeito da sua ação individual também é resultado de mecanismos estruturais que habilitam ou condicionam as suas ações, que se materializam no contexto de ação na forma de posição-prática (Cohen, I999). Em acordo com esse apontamento, Giddens (I989, p. 7) afirma que a agência tem que ver com a capacidade de se produzir um efeito: "diz respeito a eventos dos quais um indivíduo é o perpetrador, no sentido de que ele poderia, em qualquer fase de uma dada sequência de conduta, ter atuado de modo diferente".

Perante tal apontamento conceitual, objetivamos com este artigo avaliar empiricamente a capacidade da agência dos pesquisadores do campo da pesquisa em organizações e estratégia no Brasil quando imersos em redes mundos pequenos (small worlds). Coerentemente com a definição de Giddens (I989) sobre agência, buscamos operacionalizar tal objetivo avaliando, a princípio, o efeito gerado pelos agentes quanto a produtividade. Em segundo lugar, remetendo à dimensão estrutural do contexto de ação, propusemos que, em redes de coautoria, o posicionamento privilegiado dos pesquisadores quanto as lacunas estruturais (structural holes) possa ser um dos elementos que capacitam a agência. Por fim, propusemos que a configuração de faç̧ões da rede sob a forma de mundos pequenos (small worlds) também se delineia como capacitadora da agência, tanto individual quanto coletivamente, do agente.

A análise de como a estrutura social influencia o comportamento e a performance dos indivíduos é primordialmente fundamentada em estudos de análises de redes sociais (Lazega, Jourda, Mounier, \& Stofer, 2008). Mesmo se reconhecendo as limitações, ela é frutífera e coerente enquanto arcabouço metodológico e analítico (De Nooy, 2003; Emirbayer, I997; Emirbayer \& Goodwin, 1994; Kogut \& Walker, 200I; Powell, White, Koput, \& Owen-Smith, 2005; White, Owen-Smith, Moody, \& Powell, 2004). Contudo, paralelamente, modelos estatísticos multiníveis vêm sendo empregados. Comumente conhecidos como modelos lineares hierárquicos, ou modelos HLM (Bryk \& Raudenbush, 1992), eles buscam avaliar como o contexto interfere na ação social. Diante dessas duas possibilidades, buscamos neste estudo conciliar a análise de redes com modelos hierárquicos para avaliar a agência como socialmente imersa em redes de relações (Garud, Hardy, \& Maguire, 2007; Granovetter, I985).

No presente estudo, o campo científico é tomado como um tipo de sistema social, cujas redes de relações de coautoria são avaliadas como dimensão estrutural em termos de posição-prática (Cohen, I999). Isso porque há indícios de que a estrutura de relacionamento interfira tanto no processo de institucionalização das ações, quanto na capacidade de agência dos pesquisadores (Kogut \& Walker, 200I; Machado-da-Silva, Fonseca, \& Crubellate, 2005; Machado-da-Silva, Guarido 
Filho, \& Rossoni, 2006; Uzzi \& Spiro, 2005). Para tanto, buscamos avaliar o efeito da cooperação entre pesquisadores na produtividade quando imersos em redes mundos pequenos (Watts \& Strogatz, I998; Watts, I999a, I999b).

O pressuposto fundamental do fenômeno de mundos pequenos (small worl$d s)$ é de que os atores presentes numa grande rede podem se conectar a partir de um pequeno número de intermediários, tipicamente seis (Newman, 2004). Watts e Strogatz (I998) afirmam que um fenômeno small worlds ocorre quando atores em uma esparsa rede estão altamente agrupados, mas, ao mesmo tempo, estão conectados a atores fora de seus grupos por meio de um pequeno número de intermediários. Segundo Uzzi e Spiro (2005), redes small worlds aumentam a incidência de alguns mecanismos que facilitam a geração de capital social. Assim, esperamos que taxas distintas desse fenômeno acarretem em diferentes resultados em nível individual e coletivo na produtividade acadêmica. Adicionalmente, buscamos avaliar como as lacunas estruturais (Burt, I992, 2000, 2002), ou structural holes, trazem benefícios individuais para os pesquisadores enquanto forma de capital social gerado pela abertura nos laços.

Em suma, aceitando que pesquisadores podem ser vistos como agentes (Rossoni, Guarido Filho, \& Machado-da-Silva, 20Io), a imersão em redes de relações podem gerar capacidades e vantagens cumulativas ao agente (Diprete \& Eirich, 2006; Katz \& Martin, I997) quanto ao uso de vínculos e de recursos mantidos por outros autores com os quais produz, aumentando seu potencial de produção científica. Isso se refere à formação de capital social em níveis mais amplos de imersão do que os de colaboração direta, indicadas no estudo por meio das lacunas estruturais e da imersão em redes mundos pequenos.

Iniciamos discutindo a ideia de lacunas estruturais e de mundos pequenos como formas de capital social, indicando os mecanismos vinculados a cada uma delas, propondo um modelo conceitual que aponta como esses mecanismos afetam a produtividade acadêmica. Para tanto, das hipóteses desdobradas desta discussão, apresentamos formalmente formas de avaliá-las, testando-as por meio de análise multinível. Por fim, apontamos quais as implicações do estudo para o conhecimento sobre a relação entre agência, imersão e desempenho.

\section{- AgENTE E AS lacunas ESTRUTURAIS}

Pensar nos relacionamentos como elemento da capacidade de agência humana remete à noção de capital social. Segundo Lin (200I), capital social refere-se à ideia de que o investimento nas relações sociais pode ocasionar em maior 
acesso a ampla variedade de recursos. Dessa forma, a conexão com diferentes redes ou grupos aumenta as chances de aquisição de vantagens (Burt, I992, 2000, 2002). Para Lin (200I), há quatro explicações de que a imersão em redes sociais eleva os resultados das ações. Primeiramente, pela facilitação no fluxo de informação, já que uma melhor disposição dos contatos pessoais leva o indivíduo a ter acesso a oportunidades com menores custos. Em segundo lugar, os laços sociais auferem ao indivíduo uma posição privilegiada. Dessa forma, eles são mecanismos de influência (Friedkin, I998), pois têm papel crítico na tomada de decisões. Terceiro, laços sociais podem refletir certas "credenciais" ligadas à capacidade de alguns indivíduos de ter acesso a recursos de terceiros, podendo utilizá-los em benefício próprio. Por fim, as relações aumentam a identidade e o reconhecimento, pois a participação em certos grupos pode significar mérito, assim como direito de usufruir de recursos exclusivos e de estimada reputação. Esses quatro elementos - informação, influência, credenciais e reconhecimento podem explicar por que o capital social atua instrumentalmente na ação social, gerando valor além das possibilidades do indivíduo (Lin, 200I).

Normalmente atribuído a Bourdieu (I980), Coleman (I988, I990) e Lin (I982), a expressão capital social foi explorada independentemente por esses autores, podendo ser identificada duas diferentes perspectivas (Lin, 200I). A primeira delas foca o uso do capital social pelos indivíduos em seu benefício individual. Em outras palavras, o interesse é entender como os indivíduos imersos em redes sociais podem ter maiores retornos de suas ações instrumentais. Nesta perspectiva, capital social remete ao número, à força e aos recursos dos contatos (Flap, I99I), ao posicionamento privilegiado (Burt, I992) e ao grau de imersão nas relações (Uzzi, I996). Já a segunda perspectiva foca o capital social como bem coletivo. Nela, os benefícios podem ser proporcionados pelo tamanho da rede e pelo volume de capital disponível (Bourdieu, I983), em que estruturas sociais densas e coesas acomodam meios de manter e reproduzir o capital do grupo (Coleman, I990).

Essas duas perspectivas compartilham do mesmo entendimento de capital social: que ele consiste em recursos imersos em redes de relações; que podem aumentar o sucesso das ações dos atores. Mas, segundo Lin (200I), há controvérsias sob as formas estruturais adequadas para a aquisição de capital social. Alguns autores defendem a ideia de fechamento e densidade como mecanismo de capital social (Bourdieu, I983; Coleman, I990); outros a ideia de abertura (Granovetter, I973; Burt, I992). Neste estudo, defendemos ambas as formações como relevantes, já que, por um lado, redes densas e coesas são mais prováveis de promover o compartilhamento de recursos e, por outro, redes mais abertas tendem a aumentar o acesso a recursos distintos e a informações privilegiadas. Apesar de considerarmos as duas formas de capital social em redes mundos pequenos, nos 
atemos à lógica de laços fracos e abertos, em nível individual, como mecanismo explicativo da capacidade de agência dos pesquisadores. Isso porque o papel dos benefícios da cooperação, que comporta a noção de fechamento, já foi mais bem explorado em estudos anteriores (Lee \& Bozeman, 2005; Rossoni et al., 2010; Rossoni \& Hocayen-da-Silva, 2008).

Para os objetivos deste estudo, avaliamos a abertura das relações, ou a força dos laços fracos (Granovetter, I973), em relação as lacunas estruturais. Para Burt (I992), lacunas estruturais (structural holes) são os relacionamentos não redundantes entre dois contatos. Empiricamente, contatos redundantes são aqueles que apresentam algum laço direto ou indireto entre si (Burt, I992). Com isso, há duas formas de redundância: uma por meio da coesão (contato direto), em que dois contatos são considerados redundantes na extensão que apresentam relações fortes e coesas; outra por meio da equivalência estrutural (contatos indiretos), em que dois contatos são considerados estruturalmente equivalentes se apresentam as mesmas relações, mesmo que não estejam diretamente ligados (Lorrain \& White, I97I ${ }^{\text {I }}$. Assim, quanto menor o número de laços redundantes, maior o número de lacunas estruturais, havendo menor redundância de informação.

O elemento fundamental das lacunas estruturais está na extensão que a estrutura social de uma arena competitiva cria oportunidades para certos agentes por meio de seus relacionamentos (Burt, I992). Nesses termos, o controle e a participação na difusão da informação definem o capital social das lacunas estruturais (Burt, 2000, 2002). O argumento das oportunidades geradas pela intermediação (brokerage) fundamenta-se em conceitos que emergiram na Sociologia durante os anos I970, como força dos laços fracos (Granovetter, I973), centralidade de intermediação (Freeman, I979) e autonomia estrutural (Burt, I980). Contudo suas raízes são mais antigas, normalmente atribuídas à Simmel (I950), cuja ideia de tertius gaudens indica que, "quando dois brigam, é o terceiro que se beneficia". Ou seja, a expressão latina tertius gaudens (lucros de terceiros) explica a liberdade de ação e a oportunidade que um indivíduo obtém da intermediação entre duas partes não diretamente conectadas (Kirschbaum \& Vasconcelos, 2007).

Apesar de os benefícios das lacunas estruturais terem sido fundamentados por Burt (I992) em relação à competitividade dos mercados, sua estrutura formal pode ser utilizada em outras estruturas de relações (por exemplo, Burt, 2004). A partir dessa possibilidade, buscamos compreender como os pesquisadores das áreas de organizações e estratégia beneficiam-se dos relacionamentos não redundantes, com relação à produtividade acadêmica. Tal indagação é relevante, pois há evidências na literatura de que as lacunas estruturais estão associadas com

1 Ver Burt (I992, pp. I8-30) para uma extensa e detalhada explicação sobre redundância. 
benefícios individuais para os agentes, como criatividade, aprendizagem, avaliações positivas, promoções, maiores compensações e desempenho (Burt, I992, 2000, 2002, 2007).

Assim, apontamos três mecanismos vinculados às lacunas estruturais que habilitam os pesquisadores, enquanto agentes, a apresentar desempenho diferenciado. O mecanismo informacional reflete os benefícios originados do acesso à informação privilegiada e não redundante fomentada por laços com grupos distintos. Por exemplo, chamadas especiais de trabalhos, convites para colaborar em edições especiais e discussões sobre temas de ponta têm divulgação restrita. Dessa forma, quanto mais pulverizados seus laços, maior a probabilidade de que essas informações cheguem até ele. Tomando conhecimento dessas informações, ele pode utilizá-las para facilitar a publicação de seus trabalhos, não tendo que concorrer diretamente com outros estudos. Adicionalmente, lacunas estruturais aferem controle aos agentes, pois o acesso à informação pode ser utilizado em benefício próprio: pesquisadores podem negociar acesso a um canal de informação em troca de coautoria.

O segundo mecanismo aponta para a criatividade gerada pelas lacunas estruturais. Segundo Uzzi e Spiro (2005), quanto mais acessível e diverso o material criativo, e menor o risco de experimentação, maior a probabilidade de engajamento em atividades criativas. Todavia, o material criativo está imerso em convenções, reproduzidas por meio de relacionamentos, limitando sua transferência por outras formas de interação (Becker, I982). Portanto, estabelecer laços diretos com pesquisadores que possuem algum tipo de material criativo é fundamental para sua utilização. Como laços com diferentes grupos aumentam a diversidade do conteúdo, há mais chances de acessar ideias distintas, aumentando a probabilidade de que algo de novo e inovador ocorra. Nessa linha de argumentação, se o campo científico tem como norma a descoberta, estudos com maior carga de criatividade e inovação têm mais chances de serem publicados porque atendem a essa expectativa.

O terceiro e último mecanismo remete ao caráter facilitador das lacunas estruturais. Ter laços não redundantes significa ter acesso a indivíduos com diferentes recursos. Neste caso, um pesquisador pode ter um acúmulo de capacidades (Lee \& Bozeman, 2005) porque poderá utilizar recursos pertencentes a terceiros em benefício de suas próprias pesquisas (Wuchty, Jones, \& Uzzi, 2007). Por exemplo, esses recursos podem ser acessos a bancos de dados e pacotes estatísticos exclusivos, a pessoas com diferentes habilidades, a recursos financeiros, a publicações, entre outros diversos.

Enfim, considerando que a ciência é uma arena competitiva, cujos pesquisadores disputam tanto reconhecimento (Merton, I996), quanto espaço de publicação em periódicos e eventos, entendemos que esses três mecanismos - infor- 
macional, de criatividade e de facilitação - possibilitam que pesquisadores com maior proporção de lacunas estruturais tendem a ter maiores vantagens, ocasionando maior desempenho. Por isso, emanamos a seguinte hipótese:

$\mathrm{H}_{\mathrm{I}}$ : Quanto maior a proporção de lacunas estruturais um pesquisador possui, maior é sua produtividade.

\section{REDES MUNDOS PEQUENOS COMO CONTEXTO DA AGÊNCIA}

Segundo Rossoni e Guarido Filho (2009), mundos pequenos, small worlds (Watts \& Strogatz, I998; Watts, I999a, I999b), remetem à situação em que um indivíduo pode acessar qualquer outro a partir de seus relacionamentos. Tal ideia, tipicamente atribuída à Milgram (1967), aponta que em qualquer sistema de relações, de grupos de profissionais a cidadãos de uma nação, seriam necessários, em média, apenas seis "passos" para se alcançar qualquer indivíduo. Segundo Uzzi, Amaral e Reed-Tsochas (2007) e Watts (2004), a noção de mundos pequenos de Milgram (ig67) vem chamando atenção de pesquisadores porque sugere que duas características das redes de relações que eram vistas como antagônicas, homofilia e abertura, convergem sob uma estrutura mais ampla. Isso significa que, apesar de as pessoas manterem contato com número limitado de indivíduos, formando círculos afetivos, de amizade ou profissionais, uma gama muito maior de pessoas é acessada indiretamente a partir dos relacionamentos cultivados por esses contatos, já que cada um deles possui vínculos com indivíduos em círculos sociais diversos. Daí a expressão mundos pequenos: embora a maioria das pessoas não esteja relacionada diretamente entre si, elas se conectam indiretamente por meio de poucos intermediários (Lazzarini, 2007a). Em face do exposto, admite-se que todo grupo social possui certo grau de abertura, de modo que qualquer relacionamento externo a esse grupo representa um aumento exponencial de possibilidades de contatos, delineando também vias para o fluxo de informações, conhecimento e influência (Granovetter, I973).

Em termos estruturais, tem-se, por um lado, subconjuntos coesos de atores que apresentam laços relativamente fortes, diretos, intensos e frequentes (Wasserman \& Faust, I994), o que lhes permite possuir normas, valores, orientações e subculturas próprias (Moody \& White, 2003; Scott, 2000). Ademais, a coesão acomoda a base para a solidariedade, identidade e comportamento coletivo em maior intensidade entre atores de dentro do grupo do que com os de fora dele (White, I992). Por outro lado, os grupos não se encontram em situação de isolamento, mas conectados entre si, ainda que frouxamente ligados (Martins, Rosso- 
ni, Csillag, Martins, \& Pereira, 20ı0; Rossoni \& Guarido Filho, 2009). Nessa situação, ressalta-se o papel de intermediação assumido por certos atores numa rede, cujos laços por eles estabelecidos possibilitam a comunicação entre grupos distintos. Assim, laços fortes e coesos (Coleman, i988, I990) e laços fracos e lacunas estruturais (Burt, 1992; Granovetter, I973), que permeiam a análise de redes em nível local, convergem em uma estrutura de relacionamento mais ampla (nível macro), formando redes mundos pequenos.

Sob a perspectiva de mundos pequenos, o processo de desenvolvimento científico não ocorre segundo uma lógica de fragmentação, com grupos de pesquisa distintos sem interface entre si. Diferentemente, considera-se que há ligações entre eles, nos quais a informação é relativamente redundante, mantendo-se um nível de coesão necessário para que atividades se tornem familiares entre os membros dos diferentes grupos (Uzzi \& Spiro, 2005; Wagner \& Leydesdorff, 2005). Dessa forma, propriedades de mundos pequenos proveem elementos para a durabilidade das estruturas de relacionamento, bem como de práticas e valores científicos (Kogut \& Walker, 200I; Rossoni \& Machado-da-Silva, 2008), fato fundamental para entender a mútua relação entre estruturas locais e globais. A dinâmica de redes mundos pequenos permite que atores isolados atuem reproduzindo as propriedades estruturais presentes nas relações sociais, contradizendo a intuição de que atores podem romper abruptamente com a estrutura social. Nesses termos, elementos estruturais suportam a persistência de estruturas institucionais mais amplas em nível local (Giddens, I989). Tal fato é fundamental para entender a relação entre os níveis micro e macro, pois possibilita compreender como a estrutura de relacionamento local influencia a construção de estruturas globais, que recursivamente afetam a elaboração de estruturas locais, em uma relação de constante dualidade (Rossoni \& Machado-da-Silva, 2008).

Diante dos argumentos expostos, tomamos como dimensão estrutural de nível coletivo a configuração do campo científico como redes mundos pequenos; e como agentes, os pesquisadores das áreas de organizações e estratégia. Pressupondo que a capacidade de agência é condicionada pela imersão em contextos relacionais, buscamos avaliar como a produtividade acadêmica está imbricada na configuração de redes mundos pequenos. Isso porque há evidências de que a familiaridade entre pesquisadores, ocasionada pela imersão em grupos coesos, possibilita menor número de obstáculos em cooperar, afetando positivamente a produtividade (Coleman, I990). Em termos formais, coesão em mundos pequenos é avaliada por meio do coeficiente de agrupamento $(C C)$, uma medida de densidade local, que considera a conectividade entre atores (Watts \& Strogatz, I998). Ao mesmo tempo, nos fundamentamos em indícios de que a existência de laços com pesquisadores de outros grupos com diferentes perspectivas possibilite que suas habilidades e experiências sejam postas em uso de 
forma complementar em estudos científicos (Burt, 2004; Guimera, Uzzi, Spiro, \& Amaral, 2005). Assim, quanto menor a distância na rede entre esses grupos distintos, maior a possibilidade de troca, já que a distância média entre os atores $(P L)$ tende a diminuir. Portanto, seguindo Uzzi e Spiro (2005), assim como outros estudos (Burt, 2004; Fleming \& Marx, 2006; Guimera et al., 2005; Schilling $\&$ Phelps, 2007), arguimos que a mudança de distribuição de conexões e de coesão em mundos pequenos altera a probabilidade de os grupos serem mais ou menos produtivos.

Em termos específicos para esta pesquisa, o contexto de redes mundos pequenos foi operacionalizado considerando o coeficiente de agrupamento $(C C)$ e a distância média $(P L)$ em relação a redes aleatórias de mesmo tamanho (Watts, I999a). Assim, quanto mais próxima a taxa de PL (PL da rede real/PL da rede aleatória) estiver de I.o, e quanto mais a taxa de CC exceda I.o (CC da rede real/ $C C$ da rede aleatória), maior a força da configuração mundos pequenos; ou ainda, quanto maior o coeficiente small world (Q), que é a taxa de CC/ taxa de PL, maior a ocorrência desse fenômeno ${ }^{2}$. Dessa forma, o aumento na familiaridade e na proximidade entre pesquisadores sugere que redes mundos pequenos influenciem o comportamento por meio de dois mecanismos (Uzzi \& Spiro, 2005): I. estruturalmente, quanto mais uma rede torna-se um mundo pequeno (maior o coeficiente Q), maior o número de ligações entre grupos, o que potencialmente habilita a troca de experiências entre atores em diferentes pontos na rede; 2. relacionalmente, quanto maior o coeficiente $Q$, mais laços redundantes são estabelecidos, aumentando a coesão da rede, o que permite o compartilhamento de práticas. Portanto, esperamos que a conectividade e a coesão entre atores na rede afetem a produtividade individual dos pesquisadores.

Esses mecanismos estruturais e relacionais de redes mundos pequenos sugerem, por um lado, que quando o coeficiente $Q$ é baixo, a capacidade de pesquisadores serem produtivos é menor, já que apresentam poucas ligações que podem promover a troca de experiência e a complementaridade de habilidades. Por outro, se o $Q$ começa a aumentar, a rede mais conectada e coesa pode facilitar as relações entre autores, permitindo a colaboração entre diferentes grupos. Segundo Uzzi e Spiro (2005), redes mais conectadas e mais coesas facilitam o fluxo de material criativo e a colaboração entre grupos de cientistas, o que é condizente com os argumentos de Merton (I973) de colégio invisível, em que a conectividade entre autores promove o compartilhamento de ideias, informação e recursos. Ademais, segundo Granovetter (I985), a imersão relacional tende a gerar maior confiança entre pares, ocasionando maior probabilidade de eles se envolverem

2 Os detalhes sobre o cálculo do CC e do PL, assim como das estatísticas das redes que foram consideradas contexto, estão na seção 3 . 
em projetos de pesquisa na expectativa de que seus colegas colaborem. Dessa forma, a confiança associada à maior proximidade, ao reconhecimento das habilidades dos pares e à divisão do trabalho tende a fazer com que eles produzam mais estudos (Rossoni et al., 2010).

Todavia, apesar de a teoria implicar relacionamento positivo entre mundos pequenos e produtividade, outras pesquisas sugerem que a conectividade e a coesão podem afetar negativamente a produtividade. Como apontam Burt (I992) e Kogut e Walker (200I), em ambientes de alta densidade de relacionamentos, o conteúdo das informações torna-se cada vez mais redundante. McPhearson, Smith-Lovin e Cook (200I) demonstram que o aumento da homofilia diminui a diversidade, levando a reprodução de formas de pensar e de fazer. Ainda, conforme Kuhn (I978), a coesão entre cientistas pode levá-los a ver novos paradigmas como inconsistentes, especialmente quando eles já possuem uma velha tradição em pesquisa, sendo necessário que busquem interações com outros pesquisadores fora do grupo. Tais resultados sugerem que altos níveis de conectividade e coesão associados a um alto valor de $Q$ podem afetar negativamente a produtividade dos pesquisadores.

Para conciliar esses argumentos opostos acerca de mundos pequenos, nos baseamos em Uzzi e Spiro (2005), que propuseram um efeito parabólico do $Q$. Quando o valor do $Q$ é baixo, existem poucos laços entre grupos, tendendo a ser esparsos e não redundantes, levando ao isolamento dos pesquisadores com diferentes habilidades e capacidades. À medida que o coeficiente $Q$ aumenta de valor, grupos separados são ligados por pesquisadores que se conhecem, possibilitando a troca de experiências e de conhecimento. No entanto, depois de certo ponto, o aumento da conectividade e da coesão aumenta a redundância das habilidades, homogeneizando o conhecimento produzido, em que significados compartilhados e convenções tendem a imperar nos grupos (Moody \& White, 2003).

Em suma, mesmo sabendo que a colaboração e as lacunas estruturais afetam a produtividade dos pesquisadores diretamente, sugerimos que os mecanismos associados às redes small worlds afetam a produtividade dos pesquisadores tanto em nível individual, quanto em nível estrutural. Portanto, derivamos dessa relação a seguinte hipótese:

$\mathrm{H}_{2}$ : A relação entre redes mundos pequenos e produtividade acadêmica apresenta uma forma de $U$ invertido. De forma específica, a produtividade acadêmica cresce até níveis intermediários e decai quando há níveis altos ou baixos de $Q$. 


\section{DADOS E PROCEDIMENTOS METODOLÓGICOS}

O presente estudo foi delineado com base na produção científica da área de organizações e estratégia no Brasil. Para tanto, utilizamos pesquisa documental como estratégia de coleta de dados, adotando como unidade amostral os artigos científicos publicados nas áreas de organizações e estratégia em anais de eventos e periódicos classificados como A Nacional pelo Sistema Qualis da Capes no ano de 2006: EnANPAD, EnEO, 3Es, RAC, RAE, RAE-E, RAUSP, OQS, RAP e REAd3.

Identificamos 2.332 trabalhos publicados no período compreendido entre I997 e $2005^{4}$, cujos dados fomentaram o desenvolvimento de uma matriz de relações de coautoria entre os 2.072 pesquisadores do campo. Eles foram dispostos na matriz tanto nas linhas, quanto nas colunas (matriz quadrada), de forma que a presença de relacionamento entre dois pesquisadores era indicada por um, e sua ausência por valores igual a zero. Com os dados relacionais registrados em matrizes quadradas ${ }^{5}$, elaboramos as redes de cooperação entre eles por meio dos softwares Ucinet 6 (Borgatti, Everett, \& Freeman, 2002) e Pajek (Batagelj \& Mrvar, 2008), que nos permitiu verificar o grau de fragmentação do campo. Já que o objetivo do estudo remete à avaliação do efeito da posição na rede na produtividade, pesquisadores isolados, ou em componentes ${ }^{6}$ com pequena dimensão, foram desconsiderados. Assim, dos 276 componentes presentes no campo, selecionamos somente os quatro maiores, pois apresentaram tamanho satisfatório para análise da influência do contexto. Restaram, nesses quatro componentes, 945 autores $(45,6 \%)$, que serviram como base para a definição dos agrupamentos.

Desses pesquisadores, selecionamos como unidade de análise somente aqueles que tinham dois ou mais artigos publicados, já que a presença de pesquisadores com somente um único artigo publicado comprometeria os resultados da análise. Como apontado por Rossoni e Machado-da-Silva (2008), há casos em que

3 No período em que foram coletados os dados, os periódicos e eventos eram considerados os principais da área de Administração, que ao mesmo tempo incorporaram a maior parcela da produção da área e não apresentam viés de seleção.

4 Conforme alguns estudos apontaram (Acedo, Barroso, Casanueva, \& Galán, 2006; Goyal, Van der Leij, \& Moraga-González, 2006; Moody, 2004; Rossoni \& Hocayen-da-Silva, 2008), as avaliações de redes de pesquisadores tendem a apresentar padrões espaçotemporalmente duradouros, em que o período selecionado não acarretou viés significativo de análise.

5 Scott (2000) apresenta de forma detalhada como construir matrizes para dados relacionais.

6 Componentes são sub-redes em que os nós estão conectados entre si (De Nooy, Mrvar, \& Batagelj, 2005; Wasserman \& Faust, I994). 
um pesquisador produz um único artigo em sua trajetória acadêmica, mas busca colaborar com até cinco ou seis pesquisadores, distorcendo o padrão de cooperação nas áreas. Assim, buscando a manutenção da estrutura analítica e uma menor influência desse viés, removemos 472 autores com somente um único artigo publicado, sobrando os 473 casos que compõem o nível I (22,3\% do total de pesquisadores).

Já o processo de definição das unidades de análise do segundo nível foi mais complexo: buscamos identificar, dentro de cada um dos componentes, um número representativo de agrupamentos por meio da identificação de facções. Procedemos dessa forma porque as redes compostas por laços bilaterais de coautoria não apresentam nenhuma demarcação explícita. Assim, seguindo trabalhos anteriores (Burgers, Hill, \& Kim, I993; Lazzarini, 2007b; Nohria \& Garcia-Pont, I99I; Vanhaverbeke \& Noorderhaven, 200I), aplicamos o algoritmo de agrupamento chamado tabu search (Glover, I989, I990) buscando ajuste por meio do critério de Hamming (I950), que é adequado para matrizes binárias. Disponível no software Ucinet 6 (Borgatti et al., 2002), o algoritmo maximiza o ajuste dos grupos a partir da proximidade dos nós, baseando-se em um número predefinido de partições (Lazzarini, 2007b). No entanto, diferentemente de outros estudos, o campo apresentava várias sub-redes, o que nos levou a aplicar o algoritmo isoladamente nos componentes. Os dois menores, que apresentavam 3I e 49 pesquisadores, mantivemos intactos por serem pequenos; o segundo componente de maior tamanho, com 80 autores, para manter proporção com as redes anteriores, dividimos em duas facções. Por fim, o componente principal, com 785 autores, não se ajustou bem a essa proporção, sendo possível a sua divisão em somente seis facções. Mesmo assim, alguns ajustes tiveram de ser feitos para que cada um desses blocos se mantivesse totalmente conectado. Com as facções definidas, todos os pesquisadores do nível I foram vinculados aos componentes do nível 2 de forma que fosse possível realizar a análise linear hierárquica.

\section{VARIÁVEL DEPENDENTE: ARTIGOS PUBLICADOS POR PESQUISADOR}

Seguindo outros estudos que buscaram avaliar o impacto da cooperação na produtividade (Lee \& Bozeman, 2005; Martins et al., 2010; Rossoni et al., 2010; Rossoni \& Hocayen-da-Silva, 2008), empregamos como medida de produtividade do pesquisador o total de artigos publicados nas áreas de organizações e estratégia entre os anos de 1997 e 2005, em que suas estatísticas descritivas, assim como das variáveis independentes e de controle, estão expostas na Tabela i. Buscamos um horizonte de tempo maior por permitir maior número de casos, no entanto há um possível viés devido ao tempo de permanência do pesquisador no campo. 
Assim, controlamos esse efeito por meio da centralidade de grau, em que os motivos de seu uso serão apresentados depois. Além disso, diante da não linearidade da distribuição de artigos publicados, os dados foram logaritmizados pelo modelo utilizado (Poisson), cujas estatísticas também estão a seguir.

\section{TABELA I}

ESTATÍSTICA DESCRITIVA DAS VARIÁVEIS

\begin{tabular}{lcccccccc}
\hline & N & MÍNIMO & MÁXIMO & MÉDIA & DESVIO-PADRÃO & 2 & 3 & 4 \\
\hline Nível 1 & & & & & & & & \\
1. Artigos & 473 & 2 & 46 & 4,94 & 4,895 & $0,90^{*}$ & $0,60 *$ & $0,76^{*}$ \\
2. Artigos (In) & 473 & 0,69 & 3,83 & 1,33 & 0,663 & & $0,64^{*}$ & $0,71^{*}$ \\
3. Efficiency & 473 & 0,17 & 0,91 & 0,50 & 0,150 & & & $0,57^{*}$ \\
4. Degree & 473 & 1 & 27 & 4,36 & 3,477 & & & \\
\hline Nível 2 & & & & & & & & \\
6. Q & 10 & 5,09 & 87,37 & 16,88 & 25,020 & & & \\
7. Q ${ }^{2}$ & 10 & 25,96 & $7.634,39$ & 848,45 & $2.385,703$ & & & \\
8. ${ }^{2} \mathrm{Q}$ & 10 & 2,26 & 9,35 & 3,60 & 2,093 & & & \\
\hline
\end{tabular}

* Correlação é significante no nível o,or (bicaudal).

Fonte: Elaborada pelo autor.

\subsection{VARIÁVEL INDEPENDENTE DE PRIMEIRO NÍVEL: LACUNAS ESTRUTURAIS}

Entre as medidas de avaliação de lacunas estruturais, escolhemos a de eficiência dos laços (Burt, I992, p. 53), que mensura o número de contatos não redundantes EffSize em relação ao total de contatos $n$ de um ator $i$. Como trabalhamos com dados binários, utilizamos a forma simplificada da equação desenvolvida por Borgatti (1997). Formalmente, considerando que um ator $i$ apresenta $n$ número de contatos, podemos avaliar o número de contatos redundantes por meio da equação $D_{\text {alters }}=2 l / n$, em que $l$ é o número de laços entre $n$ (alters) ${ }^{7}$. Já que $D_{\text {alters }}$ indica o total de laços redundantes, consideramos como laços não redundantes EffSize como $n-D_{\text {alters. }}$. Dessa forma, a proporção de laços não redundantes

7 Borgatti (I997) utiliza a densidade dos alters por ser idêntica à medida de redundância de Burt (I992). Para detalhes, ver a nota de fim número 5 do capítulo 2 de Burt (I992). 
Efficiency é dado por EffSize/n. Utilizamos essa medida por não apresentar alta correlação com o número de contatos e por sua representatividade em relação ao engajamento nos laços fracos (Granovetter, I973). A medida de lacunas estruturais foi operacionalizada por meio do software Ucinet 6 , em que optamos por realizar o modelo restrito, que considera somente as relações do ego $i$.

\subsection{VARIÁVEL INDEPENDENTE DE SEGUNDO NÍVEL: MUNDOS PEQUENOS (SMALLL WORLDS)}

Com as dez facções definidas, que compõem o contexto de análise, avaliamos a medida de mundos pequenos para cada uma delas. Normalmente avaliada em grandes redes, por exemplo em Davis, Yoo e Baker (2003), Goyal et al. (2006), Kogut e Walker (200I), Moody (2004), Martins et al. (2010), Newman (200Ia, 200Ib, 200Ic, 2004), Rossoni e Machado-da-Silva (2008), Wagner e Leydesdorff (2005) e Watts (I999b), nós a utilizamos somente como forma de avaliar a presença de suas características nas facções, a exemplo de Rossoni e Hocayen-da-Silva (2008), que aplicaram a medida de mundos pequenos em componentes de pesquisadores da área de administração da informação. Segundo Watts e Strogatz (I998) e Watts (I999a, I999b), para quantificar uma rede mundos pequenos, duas medidas são utilizadas: a distância média entre os nós $(P L)$ e o coeficiente de agrupamento $(C C)$. PL indica o número médio de intermediários, os graus de separação, entre um dado ator a todos os demais (Uzzi et al., 2007). Assim, quanto mais próximo os atores estão entre si, menor a distância média entre eles na rede. Já o $C C$ indica como os contatos de um ator estão recursivamente ligados entre si. Em outras palavras, quanto maior o número de cliques $^{8}$ que eles formam, maior o agrupamento da rede. Formalmente, podemos definir o coeficiente de agrupamento $C C$ como $3 \times$ número de cliques/número de trios conectados ${ }^{9}$. Ele pode variar de $\circ$ a I, em que redes totalmente agrupadas apresentam coeficiente I, enquanto aquelas totalmente desagrupadas apresentam coeficiente $o$.

Como redes podem apresentar diferentes tamanhos, a efetividade do que seria uma rede agrupada e com pequena distância entre os nós varia acerca desse fator. Por isso, Watts e Strogatz (I998) definiram que seria relevante compará-las com redes aleatórias do mesmo tamanho, mais precisamente com suas medidas de agrupamento e de distância. Seguindo esses autores, definimos o coeficiente de agrupamento aleatório como $k / n$ e a distância média aleatória como

8 Clique é uma sub-rede ou subgrafo completo de três ou mais nós, em que todos os pontos estão diretamente conectados (De Nooy et al., 2005; Scott, 2000; Wasserman \& Faust, I994).

9 O número de cliques é multiplicado por três porque eles podem apresentar três tipos de configurações de tríades. Para detalhes, ver Wasserman e Faust (I994). 
$\ln (n) / \ln (k)$, em que $n$ é o número de pesquisadores e $k$ é a quantidade de laços ${ }^{10}$. Depois disso, comparamos os valores aleatórios com os reais, em que foram considerados mundos pequenos se a $P L$ taxa (PL real/PL aleatório) e a CC taxa (CC real/CC aleatório) fossem ambas maior do que I. Por fim, seguindo Uzzi e Spiro (2005), definimos como variável independente de segundo nível o coeficiente small world $Q$ (CC taxa PL taxa). Quanto maior esse indicador, maior o efeito mundos pequenos. Todavia, como exposto no quadro teórico e na hipótese 2, esperamos um efeito curvilinear do $Q$ na produtividade acadêmica, por isso calculamos o quadrado e a raiz da variável para avaliar esse efeito (ver Tabela I para estatísticas descritivas).

\subsection{VARIÁVEL DE CONTROLE: CENTRALIDADE DE GRAU}

Como indicado na literatura, a produtividade acadêmica apresenta forte relacionamento com o número de colaboradores que um pesquisador detém (Rossoni et al., 2010; Rossoni \& Hocayen-da-Silva, 2008; Lee \& Bozeman, 2005). Buscamos controlar esse efeito por meio da centralidade de grau dos autores, que é medido pelo número de laços que um ator possui com outros (Wasserman \& Faust, 1994). Além disso, por ser altamente correlacionada com o tempo de atividade do pesquisador no campo, ela também controla esse efeito ${ }^{\text {II }}$.

\subsection{MOdELO MULTINíVEL E PROCESSO DE ANÁLISE}

Para avaliar a influência das lacunas estruturais (variável de primeiro nível) e do contexto de mundos pequenos (variável de segundo nível) na produtividade acadêmica, utilizamos um modelo linear hierárquico generalizado (HGLM) de dois níveis. De maneira geral, aplicamos esse modelo porque ele considera tanto o efeito direto das variáveis no primeiro nível quanto a influência de cada contexto (e suas variáveis) de forma individual (Luke, 2004). Já que os pesquisadores estão aninhados em redes de relações, ele é adequado para se entender o efeito cruzado da configuração de mundos pequenos na produtividade acadêmica (Snijders \& Bosker, I999). Especificamente, diante da não linearidade da variável dependente, que apresenta uma distribuição hiperbólica, utilizamos o modelo generalizado com função Poisson Log Link. Segundo Raudenbush, Bryk e Congdon (2004) e Snijders e Bosker (I999), modelos com ajuste de distribuição Poisson

10 Ver Watts (I999b) e Uzzi et al. (2007) para uma detalhada explicação do cálculo dos indicadores aleatórios.

11 Inserimos a variável tempo no modelo, no entanto esta não se mostrou significativa quando em conjunto com a centralidade de grau. Por isso decidimos excluí-la para diminuir o número de parâmetros do modelo multinível. 
são adequados quando a variável dependente é uma contagem de eventos, em que a probabilidade de ocorrência tende a cair, como no caso do número de artigos publicados por pesquisador. Basicamente o modelo transforma a variável dependente em logaritmo natural, estimando o modelo por meio de uma pseudoverossimilhança $(P Q L)^{12}$.

Estruturalmente, considerando que um autor publicou $\lambda$ artigos, representa-se no primeiro nível como variável dependente o logaritmo de $\lambda$, que é igual a $\eta$. Com isso, temos a média da produtividade representada por $\beta_{\circ}$, a influência da cooperação representada por $\beta_{\mathrm{I}}$ e a influência das lacunas estruturais definida por $\beta_{2}$.

\section{Nível I}

$$
\begin{aligned}
& E(\text { Artigos } \mid \beta)=\lambda \\
& \log [\lambda]=\eta \\
& \eta=\beta_{\circ}+\beta_{1}^{*}(\text { Degree })+\beta_{2}{ }^{*}(\text { Efficienc } \gamma)
\end{aligned}
$$

\section{Nível 2}

$$
\begin{aligned}
& \beta_{O}=\gamma_{O O}+\gamma_{O I} *\left(V^{2} Q\right)+v_{0} \\
& \beta_{I}=\gamma_{10}+v_{I} \\
& \beta_{2}=\gamma_{20}+v_{2}
\end{aligned}
$$

Todavia, como estamos interessados em avaliar a influência do contexto relacional (nível 2), cada um dos betas do primeiro nível foram decompostos em relação a cada uma das facções, em que: $\gamma_{\circ \circ}$ representa a produtividade média para toda a amostra e $v_{\circ}$ a variância entre os grupos; $\gamma_{\text {Io }}$ representa a colaboração média e $v_{1}$ a variação; $\gamma_{20}$ é a influência média das lacunas estruturais e $v_{2}$ a variação. Adicionalmente, para avaliar a hipótese sobre mundos pequenos, estimamos seu efeito por meio de $\gamma_{\text {oI }}$ buscando relação direta com a produtividade (Intercept as Outcomes Model). Em resumo, as equações simultâneas anteriores podem ser representadas em forma de modelo misto, como:

$$
\begin{aligned}
\eta= & \gamma_{00}+\gamma_{01}^{*}\left(\sqrt{ }^{2} Q\right)+\gamma_{10} *(\text { Degree })+\gamma_{20} *(\text { Efficiency })+v_{0}+v_{1}^{*} *(\text { Degree })+ \\
& v_{2}^{*}(\text { Efficienc } \gamma)
\end{aligned}
$$

Em que $\eta$ é a variável dependente, $\gamma$ são os efeitos fixos e $v$ são os efeitos variáveis entre as redes. Buscamos comparar esse modelo com o de mundos pequenos sem transformação e com o de mundos pequenos com efeito quadrado

12 Utilizamos o modelo restrito por ser mais robusto, que calcula a variância por meio da estimação $P Q L$. Detalhes técnicos da estimação podem ser visto em Raudenbush et al. (2004). 
para verificar a relevância do efeito curvilinear. Antes dessas comparações, como sugerido por Bryk e Raudenbush (I992) e Luke (2004), construímos três modelos antecedentes ao modelo final com o objetivo de avaliar a estabilidade e a relevância das variáveis. O primeiro modelo (One-Way ANOVA with Random Effects) foi utilizado para verificar se a produtividade variava entre os grupos; já no segundo (One-Way ANCOVA with Random Effects), avaliamos se as variáveis independentes do primeiro nível apresentavam relação significativa, mas sem levar em conta a variância entre os grupos, o que foi considerado no último modelo (Random Coefficients Model).

Por fim, para representar a relação curvilinear entre produtividade e mundos pequenos, utilizamos a média de artigos publicados em cada rede, regredindo-a em relação ao indicador de mundos pequenos $(Q)$ por meio de uma equação quadrática. Tal relação foi representada em gráfico, objetivando realçar o efeito do contexto (nível 2).

\section{RESULTADOS}

Na Figura I, estão ilustrados os quatro componentes de maior tamanho, extraídos da estrutura de relações de coautoria do campo da pesquisa em organizações e estratégia no Brasil. Na figura, cada nó representa um pesquisador, e cada laço um relacionamento de coautoria. Os componentes, em conjunto, representam 45,6\% (945 autores) dos 2.072 pesquisadores, cujo componente principal $(C 1)$ engloba a maior parte: 785 pesquisadores $(37,9 \%$ do total do campo). Os outros três componentes apresentam tamanho bem mais reduzido: o componente $C_{2}$ apresenta 80 autores $(3,9 \%)$, o $C_{3}$ tem 49 pesquisadores $(2,4 \%)$ e o $C_{4}$ apresenta 3I autores (I,5\%). Como os componentes foram fracionados para a análise de mundos pequenos, os pesquisadores pertencentes a cada uma das facções estão identificados por cores diferentes. O componente principal $\left(C_{1}\right)$ foi fragmentado em seis porções menores devido ao seu maior tamanho. Com isso obtivemos uma grande facção, com 559 autores, e outras cinco com tamanho bem mais reduzido: 30, 3I, 32, 4I e 92 autores. O componente $C_{2}$ foi recortado em duas facções menores (52 e 28 pesquisadores). Já os componentes $C_{3}$ e $C_{4}$ não foram divididos por terem pequenas proporções. Vale destacar que vários tipos de ajustes foram utilizados para tentar diminuir o tamanho das facções do componente principal objetivando uma distribuição mais homogênea, todavia diminuíam severamente a acurácia dos agrupamentos. No entanto, apesar dessa diferença, modelos multiníveis são robustos para agrupamentos heterogêneos (Luke, 2004), não enviesando os resultados. 


\section{FIGURA I}

\section{COMPONENTES E FACÇÕES DOS PESQUISADORES}

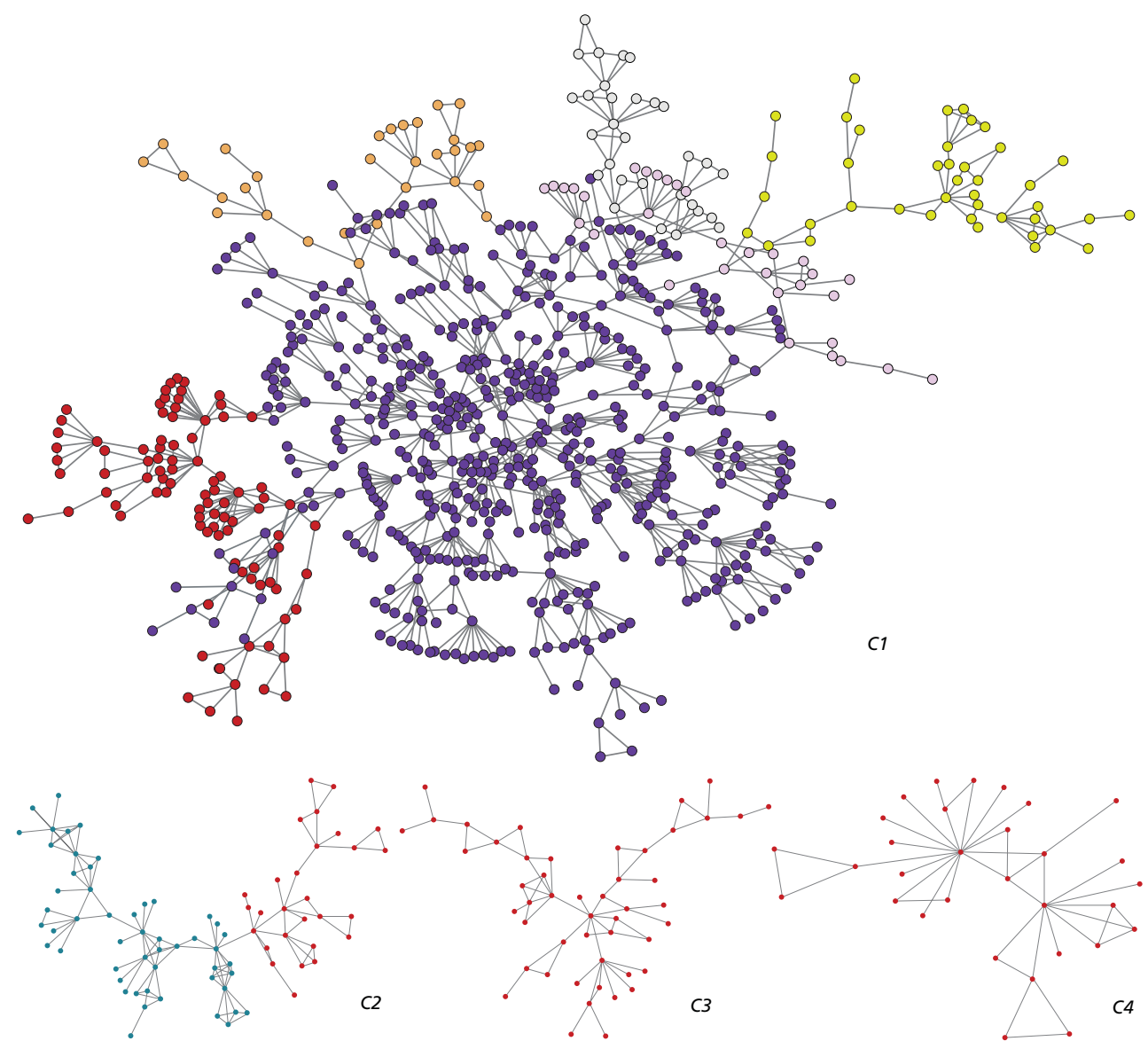

O componente principal $\left(C_{1}\right)$ é formado por 785 autores, formando 6 facções. O componente $C_{2}$ possuiu 80 autores, divididos em duas facções. O componente $C_{3}$ e $C_{4}$ apresentam somente uma facção cada, com 49 e 3I autores, respectivamente. As distinções entre as cores representam as diferentes facções. Na análise, foram considerados somente os pesquisadores com dois ou mais artigos publicados.

Fonte: Elaborada pelo autor.

Em concordância com estudos anteriores (Acedo et al., 2006; Goyal et al., 2006; Moody, 2004; Rossoni \& Hocayen-da-Silva, 2008), os resultados apontam para grande fragmentação do campo da pesquisa em organizações e estratégia, a exemplo de outras disciplinas das Ciências Sociais, como Economia, Sociologia e Administração da Informação, cujos componentes principais aglutinaram, no 
máximo, 40\% dos pesquisadores. A fragmentação é notória se comparado o componente principal do campo em estudo com o de outras disciplinas como Matemática, Física e Biologia, que envolvem $82 \%$ a 92\% de seus pesquisadores (Newman, 200IC, 2004). Segundo Rossoni e Machado-da-Silva (2008), a formação de diversos componentes sob uma mesma disciplina tende a refletir a heterogeneidade de temas e pesquisas, comum nas Ciências Sociais. Os autores, baseados em Fuchs (I993), argumentaram que a maior diversidade de recursos entre pesquisadores nas Ciências Sociais, assim como a incerteza acerca das interpretações dos resultados, permitem que diferentes grupos persistam, formando sistemas de significação distintos. Com isso, essas diferentes esferas tendem a condicionar os relacionamentos estabelecidos no campo, o que leva à formação de redes não interligadas.

Tais argumentos nos levaram a considerar esses diferentes componentes, mais precisamente as facções, como contextos distintos para a agência. Assim, como explicitado nos procedimentos metodológicos, fomentamos para cada uma das facções as estatísticas de mundos pequenos, que estão expostas na Tabela 2. As colunas representam cada uma das facções e as linhas apresentam três tipos de informações: no primeiro, dados observados, estão indicados os resultados reais da análise; no segundo, dados aleatórios, apontam-se os indicadores esperados em redes idênticas, porém com formação simulada de maneira aleatória; o terceiro, indicadores, relaciona os dados observados com os aleatórios de acordo com o sugerido por Watts e Strogatz (I998).

\section{TABELA 2}

ESTATISTICAS DE MUNDOS PEQUENOS DAS FACÇÖES

\begin{tabular}{|c|c|c|c|c|c|c|c|c|c|c|}
\hline FACÇÃO & 1 & 2 & 3 & 4 & 5 & 6 & 7 & 8 & 9 & 10 \\
\hline \multicolumn{11}{|l|}{ Dados observados } \\
\hline Autores $(n)$ & 32 & 92 & 30 & 31 & 559 & 41 & 52 & 28 & 31 & 49 \\
\hline Autores com dois ou mais artigos (amostra) & 16 & 39 & 14 & 15 & 289 & 24 & 22 & 14 & 12 & 28 \\
\hline Média de laços por autor (k) & 2,56 & 3,26 & 2,80 & 3,42 & 3,21 & 2,83 & 3,65 & 2,79 & 2,71 & 2,57 \\
\hline PL: Distância Média & 4,04 & 4,63 & 4,47 & 2,46 & 7,11 & 4,31 & 4,13 & 3,54 & 2,54 & 4,38 \\
\hline CC: Coeficiente de Agrupamento & 0,62 & 0,74 & 0,64 & 0,81 & 0,66 & 0,56 & 0,75 & 0,71 & 0,79 & 0,57 \\
\hline \multicolumn{11}{|l|}{ Dados aleatórios } \\
\hline CC: Coeficiente de Agrupamento esperado $(\mathrm{k} / \mathrm{n})$ & 0,08 & 0,04 & 0,09 & 0,11 & 0,01 & 0,07 & 0,07 & 0,10 & 0,09 & 0,05 \\
\hline PL: Distância Média Esperada $(\ln (n) / \ln (k))$ & 3,68 & 3,83 & 3,30 & 2,79 & 5,42 & 3,57 & 3,05 & 3,25 & 3,44 & 4,12 \\
\hline \multicolumn{11}{|l|}{ Indicadores } \\
\hline$P L$ taxa (PL real/PL aleatório) & 1,10 & 1,21 & 1,35 & 0,88 & 1,31 & 1,21 & 1,35 & 1,09 & 0,74 & 1,06 \\
\hline CC taxa (CC real/CC aleatório) & 7,77 & 20,96 & 6,89 & 7,37 & 114,65 & 8,14 & 10,66 & 7,15 & 9,04 & 10,79 \\
\hline Q: Coeficiente Small World (CC taxa/PL taxa) & 7,08 & 17,32 & 5,09 & 8,38 & 87,37 & 6,74 & 7,87 & 6,57 & 12,26 & 10,14 \\
\hline
\end{tabular}

Fonte: Elaborada pelo autor. 
Objetivando maior homocedasticidade da relação entre variáveis, consideramos como amostra somente aqueles pesquisadores que publicaram dois ou mais artigos no período. Restaram então 473 pesquisadores, distribuídos em Io facções diferentes, em que a menor possui I2 pesquisadores e a maior 289. Mesmo havendo certa discrepância entre o valor mínimo e máximo de autores, se desconsiderada a maior facção, a diferença de casos selecionados por facção é pequena ${ }^{\mathrm{I} 3}$. Já as estatísticas de mundos pequenos foram realizadas considerando todos os autores das facções (n), pois, caso contrário, as redes seriam descaracterizadas. Comparando as facções entre si, verificamos que a cooperação entre pesquisadores, medida por meio da média de laços por autor $(k)$, variou de 2,56 para a facção I até 3,65 para a facção 7, não apresentando qualquer tipo de padrão com as demais estatísticas das facções. A distância média entre os pesquisadores $(P L)$ tende a ser menor em facções de menor tamanho, como a facção 4 (distância média de $2,46)$, havendo tendência de aumento quando o tamanho do componente aumenta (Spearman's rho $=0,644, p=0,044)$. Já o coeficiente de agrupamento $(C C)$ não apresentou variação em relação às outras medidas como tamanho da rede $(n)$, média de laços $(k)$ e distância média $(P L)$. Estes dois últimos resultados em conjunto, a invariabilidade do coeficiente de agrupamento e uma leve tendência de aumento da distância média em relação ao tamanho da rede caracterizam a durabilidade de redes mundos pequenos (Watts, I999b): ao contrário do que ocorre com o aumento de tamanho de redes aleatórias, cuja distância entre nós tende a aumentar, e o coeficiente de agrupamento tende a cair, em redes reais do tipo mundos pequenos, a proximidade $(P L)$ e a coesão $(C C)$ variam muito pouco. Com isso, tais estruturas garantem que os relacionamentos não se fragmentem em porções cada vez menores.

Para corroborar essa afirmação, os resultados da distância média observada entre os nós foram próximos aos das distâncias médias esperadas para cada facção, excedendo essa relação, no máximo, em 35\% (PL taxa da facção 3 e 4). Ademais, o coeficiente de agrupamento real foi bem superior ao aleatório em todas as facções, indicando que o tamanho da rede não afetou a coesão dos relacionamentos. Como visto no indicador CC taxa, a coesão encontrada nas redes superou em, no mínimo, sete vezes o valor esperado (CC taxa do fator $3=6,89$ ). Esses dois resultados em conjunto evidenciam a presença de estruturas relacionais do tipo mundos pequenos, sendo operacionalmente apontados pelo indicador Q. Seguindo os parâmetros definidos por Uzzi e Spiro (2005), todas as facções observadas no estudo podem ser consideradas redes mundos pequenos, já

13 Como apontado por Snijders e Bosker (I999), a discrepância acerca do tamanho dos grupos não apresenta grandes problemas na avaliação, pois modelos hierárquicos utilizam-se do teste Qui-quadrado para avaliar a diferença entre eles. 
que o valor do coeficiente $Q$ excedeu, em todos os casos, valor I. O menor coeficiente foi observado na facção $3(Q=5,09)$ e o maior na facção $5(87,37)$.

Perante as evidências de que cada facção está estruturada na forma de mundos pequenos, buscamos avaliar o efeito desta configuração na produtividade acadêmica, considerando o coeficiente $Q$ de cada facção como variável de contexto. Para tanto, primeiramente analisamos esse efeito, assim como da cooperação direta e das lacunas estruturais, na produtividade individual dos pesquisadores, cujos resultados do modelo hierárquico generalizado final estão na Tabela 3. Como utilizamos um modelo Poisson, a interpretação dos resultados é feita por meio do expoente do coeficiente beta (Event Rate Ratio).

\section{TABELA 3}

\section{EFEITO DAS LACUNAS ESTRUTURAIS E DA REDE MUNDOS PEQUENOS NA PRODUTIVIDADE}

Intercept as Outcomes Model (HGML)

\begin{tabular}{|c|c|c|c|c|c|c|}
\hline FIXED EFFECT & COEFFICIENT & $\begin{array}{l}\text { EVENT RATE } \\
\text { RATIO }\end{array}$ & $\begin{array}{c}\text { STANDARD ERROR } \\
\text { (ROBUST) }\end{array}$ & T-RATIO & d.f. & P-VALUE \\
\hline Intercept $\left(\gamma_{00}\right)$ & $-0,027$ & 0,974 & 0,141 & $-0,189$ & 8 & 0,855 \\
\hline Raiz ${ }^{2}$ Small World $\left(\gamma_{01}\right)$ - Nivel 2 & 0,043 & 1,044 & 0,008 & 5,387 & 8 & 0,000 \\
\hline Degree $\left(\gamma_{10}\right)$ & 0,082 & 1,085 & 0,009 & 9,528 & 9 & 0,000 \\
\hline Efficiency $\left(\gamma_{20}\right)$ & 1,714 & 5,554 & 0,322 & 5,327 & 9 & 0,000 \\
\hline RANDOM EFFECTS & $\begin{array}{l}\text { STANDARD } \\
\text { DEVIATION }\end{array}$ & & $\begin{array}{l}\text { VARIANCE } \\
\text { COMPONENT }\end{array}$ & $\chi^{2}$ & d.f. & P-VALUE \\
\hline Intercept $\left(v_{0}\right)$ & 0,310 & & 0,096 & 23,264 & 8 & 0,003 \\
\hline Degree $\left(v_{1}\right)$ & 0,015 & & 0,0002 & 22,401 & 9 & 0,008 \\
\hline Efficiency $\left(v_{2}\right)$ & 0,574 & & 0,330 & 22,648 & 9 & 0,007 \\
\hline
\end{tabular}

Model: Poisson Log Link Function nI: 473 n2: Io

Deviance (-2LL): I455,332 AIC: 1469,3322 BIC: 1498,4459

Fonte: Elaborada pelo autor.

Avaliando os efeitos fixos, que indicam a relação das variáveis em toda a amostra, observamos que o número de laços (Degree), tratado neste estudo como variável de controle, afeta positiva e significativamente a produtividade individual dos pesquisadores $(\exp ($ beta $)=\mathrm{I}, 085, p<0,00 \mathrm{I})$, em que cada colaborador a mais que um pesquisador possuir o leva a um incremento de $\mathrm{I}, 085$ artigos em média. Esse resultado, já apontado em estudos anteriores, indica a importância da colaboração na produtividade, cujas implicações vão além dos relacionamentos dire- 
tos, mas são ampliados pelos laços indiretos. Por isso, incorporamos no estudo a avaliação do efeito da proporção de lacunas estruturais (structural holes) na produtividade. Por meio da medida Efficiency, verificamos que, quanto maior a proporção de lacunas estruturais um autor apresentar, maior será, em média, sua produtividade $(\exp ($ beta $)=5,554, p<0,00 \mathrm{I})$, corroborando a Hipótese I. Na amostra, podemos observar que um aumento de io\% nas lacunas está associado a um aumento de $55 \%$ nos artigos publicados, indicando a força dos laços não redundantes na produtividade acadêmica. Depois, avaliamos o efeito dos mundos pequenos na produtividade individual dos pesquisadores. Como partimos do pressuposto de que esse efeito é curvilinear, avaliamos a raiz quadrada da variável Small World. Os resultados indicam uma associação positiva e significativa entre produtividade e mundos pequenos $(\exp (b e t a)=\mathrm{I}, 044, p<0,00 \mathrm{I})$, como apontado na Hipótese 2. Assim, para cada aumento absoluto na variável $\sqrt{ }^{2} Q$, a produtividade do pesquisador tende a aumentar em I, $8 \%{ }^{\mathrm{I}}$

Adicionalmente, avaliando os efeitos dos grupos (Random Effects), podemos afirmar que o contexto de mundos pequenos afeta significativamente a produtividade em caráter coletivo, pois o seu efeito mostrou-se variante quando comparadas as diferentes facções $\left(v_{\circ}=0,096, p=0,003\right)$, refletindo o que foi proposto na Hipótese 2. Verificamos também que o número de laços (Degree $=0,0002$, $p=0,008$ ) e as lacunas estruturais (Efficiency $=0,330, p=0,007$ ) afetam a produtividade de forma contingencial, já que diferentes facções apresentaram relacionamentos distintos entre essas variáveis. Esses resultados em conjunto são evidências empíricas do caráter condicional da agência diante de sua imersão em diferentes contextos.

Por fim, buscamos ilustrar o efeito coletivo de mundos pequenos na produtividade dos pesquisadores por meio da avaliação do relacionamento curvilinear entre a produtividade média nas facções e o coeficiente $Q$ de Small Worlds. Como podemos observar no Gráfico I, os pontos, que indicam a média de produtividade, apresentam-se bem próximos da curva de tendência, cujo coeficiente de explicação mostrou-se forte e significativo $\left(R^{2}=72,3 \%, F=9,156, p=0,0\right.$ II,$n=$ IO $)$. Assim, como representado no gráfico, o aumento do coeficiente $Q$ está associado ao aumento da produtividade média dos pesquisadores até determinado ponto, tendendo a cair quando esses valores são muito altos. Associando esse resultado à diferença significativa entre as facções, evidenciada na análise dos componentes da variância, podemos afirmar que a configuração de mundos pequenos afeta a

14 Como o efeito da Raiz ${ }^{2}$ de Small World interage com o intercepto, calculamos o seu efeito considerando o incremento na produtividade do pesquisador [(I,O44-I $)^{*} \mathrm{IO}$ ] descontando o efeito do intercepto [(0,974I)*Ioo]. Assim, diminuindo o efeito de $4,4 \%$ da $\sqrt{ }^{2} Q$ pelo efeito do intercepto $\gamma_{\circ \circ}(2,6 \%)$, obtivemos um impacto de $\mathrm{I}, 8 \%$ na produtividade associada ao contexto relacional de mundos pequenos. 
produtividade em nível estrutural. Portanto, diante das evidências de relacionamento entre mundos pequenos e produtividade, tanto em nível individual, quanto coletivo, corrobora-se a Hipótese 2.

\section{GRÁFICO I}

\section{RELAÇÃO CURVILINEAR ENTRE PRODUTIVIDADE E MUNDOS PEQUENOS}

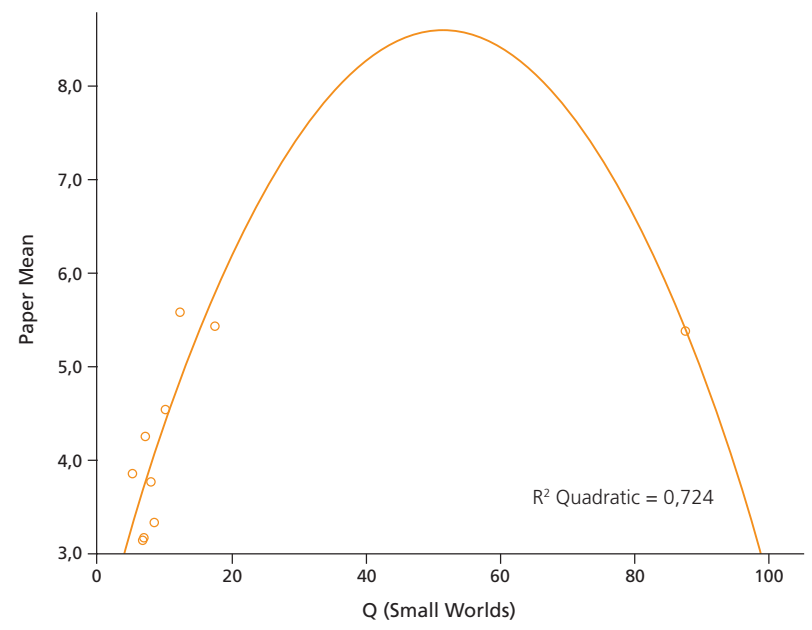

Fonte: Elaborado pelo autor.

\section{DISCUSSÃO E CONCLUSÃO}

Buscando compreender a capacidade da agência dos pesquisadores do campo da pesquisa em organizações e estratégia no Brasil, neste artigo, avaliamos como a posição dos pesquisadores em termos de lacunas estruturais e da imersão em redes mundos pequenos (small worlds) afetam a produtividade. Como indicado na Hipótese I, foi observado que aqueles pesquisadores que oportunizaram maior proporção de laços não redundantes (structural holes) tendem a ser mais produtivos. Coerentemente com estudos anteriores (Burt, I992, 2000, 2002), os resultados evidenciam que o capital social formado pelos laços fracos aumenta os benefícios para o ator em nível individual. Basicamente, buscamos explicar tal fenômeno no campo da pesquisa por meio de três mecanismos: o informacional, que remete ao acesso à informação privilegiada e não redundante; o de criatividade, que evidência as possibilidades geradas pelo acesso a diferentes ideias, 
aumentando a probabilidade de inovação; o facilitador, que indica que os laços fracos tendem a facilitar o acesso a recursos de terceiros. Pressupondo que o campo científico é competitivo, no qual pesquisadores disputam espaço por publicação, estudos inovadores, criativos e com métodos de análise robustos tendem ter maior facilidade de inserção. Portanto, autores que apresentam posicionamento privilegiado no campo em termos das lacunas estruturais estão mais sujeitos a apresentar estudos deste tipo.

Nosso estudo também apontou que o efeito da cooperação na produtividade é condicionado pela imersão em redes mundos pequenos. Os resultados mostram que a imersão em diferentes redes condiciona o relacionamento entre cooperação e produtividade, cujos pesquisadores em diferentes grupos apresentaram desempenho distinto. Além disso, como apontado na Hipótese 2, verificamos que redes mundos pequenos afetam diretamente esses níveis de produtividade, porém de forma curvilínea. De maneira condizente com a literatura, baixos níveis de $Q$ (coeficiente Small Worlds) indicam menor coesão e conectividade entre pesquisadores dificultando o desenvolvimento de capital social, o que gerou menor produtividade. Em níveis intermediários de $Q$, verificamos maior produtividade, já que esse tipo de contexto possibilita que o capital social se desenvolva, mas sem coibir o conteúdo das relações, inibindo as inovações. Por fim, quanto o coeficiente $Q$ se mostrou mais elevado, verificamos que a produtividade caiu, indicando que, quando a coesão e a conectividade são muito altas, o capital social tende a perder força diante de maior homogeneidade e redundância de conteúdo informacional.

Por fim, avaliando as relações entre facções, podemos evidenciar que, além de as redes mundos pequenos afetarem a produtividade em nível individual, elas também afetam o desempenho dos grupos de forma coletiva, indicando que os arranjos entre pesquisadores tanto influenciam quanto são influenciados pela sua formação estrutural. Podemos concluir que tal relação entre agência e contexto é uma evidência de que formas estruturadas de organização de campos sociais podem ser analisadas a partir da ação dos agentes, cujos resultados extrapolam sua ação direta, ganhando contornos próprios diante da configuração desses campos. Apesar da restrição do contexto como rede de relações, só foi possível compreender o efeito dos mecanismos estruturais e relacionais na produtividade dos pesquisadores porque buscamos uma análise relacional. Ademais, sem a complementaridade da análise multinível, não seria possível inferir o efeito do contexto de mundos pequenos na formação do capital social, que foi evidenciado por taxas diferenciadas de produtividade. Isso não leva a tomar redes mundos pequenos como determinantes da ação, mas como um empreendimento que emerge da colaboração entre pesquisadores, cujas ações apresentam consequên- 
cias impremeditadas, próximas a de um sistema auto-organizado (Wagner \& Leydesdorff, 2005).

\section{1 |IMPLICAÇÕES TEÓRICAS}

Diante dos argumentos apresentados no trabalho, algumas implicações teóricas podem ser apontadas. A primeira delas foca a relação entre agente e contexto. Para a teoria institucional de análise, o estudo aponta uma forma de avaliar a relação entre agência e estrutura focando o entendimento do agente como construtor de padrões sociais, em vez de focar os mecanismos isomórficos que constrangem as suas ações. Mesmo havendo a limitação de considerar como contexto somente a estrutura de relações, tal delineamento possibilitou demonstrar como ações entre pares de pesquisadores emergem em padrões mais amplos de interação, implicando formas diferenciadas de capital social. Conceitualmente, o entendimento do agente em campos sociais deve ser evidenciado sempre considerando seu contexto (estrutura), assim como sua capacidade de gerar efeito. Para nós, essa é a reclamação fundamental do conceito de agente: só há agente se houver estrutura. Com isso, só é possível compreender como alguns agentes são capazes de ter melhores resultados se forem considerados imersos socialmente.

Vale destacar que não estamos fundindo o conceito de agência ao de indivíduo, muito menos ao da ação, apesar de reconhecermos a interdependência entre essas unidades. Para nós, aceitar o agente como socialmente imerso é admitir que o resultado de sua ação é contingencial ao seu posicionamento na estrutura social. Isso não é a mesma coisa que dizer que a estrutura também afeta a ação. Claramente, é preciso entender que, se é coerente dizer que existe agência socialmente imersa, é necessário aceitar que a agência se constitui quando o indivíduo incorpora os elementos estruturais, afetando o efeito de suas ações assim como das dos outros. Em outros termos, o indivíduo, enquanto agente, é um vetor de suas próprias ações, ao mesmo tempo que reflete os padrões e as expectativas presentes na estrutura, sendo difícil dissociar se o efeito da ação pertence à estrutura ou ao indivíduo, mas que, sem dúvidas, pode ser atribuído ao agente de forma individual.

\subsection{IMPLICAÇÕES PRÁTICAS}

Como a parte empírica do estudo ficou circunscrita no campo da pesquisa em organizações e estratégia, as implicações práticas necessariamente só podem se reportar a esse fenômeno. Em primeiro lugar, o estudo destaca o papel dos relacionamentos com os pares como mecanismo facilitador da produtividade. Pesquisadores que conseguem angariar mais colaboradores tendem a produzir 
mais. No entanto, os relacionamentos não redundantes apresentam vantagens adicionais, já que podem ser fonte de novas ideias, novos recursos e fontes diferenciadas de informação. Assim, qualquer tipo de atividade que aproxime pesquisadores com habilidades distintas e que possuam diferentes recursos deve ser buscada. Por exemplo, programas como o de professor visitante, convênios entre instituições de diferentes países, grupos de pesquisa multidisciplinares, entre várias outras ações podem facilitar o contato entre pesquisadores. Porém, o resultado acerca da influência da coesão e da proximidade ocasionada por mundos pequenos aponta para a necessidade de que tais laços sejam estabelecidos com grupos de pesquisadores, pois a cooperação em termos de pesquisa conjunta necessita de alto grau de familiaridade entre pares. Sem isso, a cooperação tende a não apresentar qualquer vantagem. Ou seja, para que a cooperação seja efetiva na formação de capital social, maiores níveis de abertura dos laços devem ser acompanhados de relações mais duráveis ou de maior frequência.

Em adição, se diferentes arranjos relacionais implicam diferentes níveis de resultados, agências de fomento, assim como programas de pós-graduação, devem aprender a monitorar as relações em todo o campo, já que o desempenho de algumas áreas pode estar atrelado a arranjos mais amplos, como evidenciado em nosso estudo. Como aponta Barabasi (2005), a ciência no mundo contemporâneo não é mais um empreendimento individual, mas uma atividade coletiva cujo avanço está cada vez mais vinculado a formas de manutenção das relações, assim como a formas de compartilhamento de capital social. Em suma, a discussão da agência como socialmente imersa é importante porque fomenta novas avenidas para a compreensão de como resultados individuais e organizacionais são afetados pelo contexto social, tanto em nível individual, quanto coletivo.

\subsection{LIMITAÇÕES E ESTUDOS FUTUROS}

Entre as limitações do estudo, algumas merecem apontamento. Uma delas é a forma arbitrária de definir os contextos por meio da análise de facções. Facções com diferentes tamanhos apontam para resultados distintos, principalmente em fenômenos com dados relacionais. Além disso, como há tendência de formação de centros altamente agrupados em campos da pesquisa (Rossoni \& Guarido Filho, 2009), a maior parte do componente principal agrupou-se em uma única facção, o que a levou a ter tamanho desproporcionalmente maior que as demais. Outra limitação cabe à análise estática usando-se dados de uma janela de tempo de nove anos. Com isso o fator tempo, mesmo buscando ser controlado, apresenta efeito sob os resultados. Portanto, outros estudos podem trabalhar com amostras maiores de pesquisadores e com maior número de grupos, envolvendo outras 
áreas do conhecimento, buscando analisar períodos de tempo mais restritos, de dois a três anos, porém com recorte longitudinal. A existência de três ou mais períodos de análise possibilita avaliar quais variáveis se comportam como exógenas e endógenas, fomentando maior clareza na explicação dos mecanismos que afetam a formação de capital social.

Outra limitação cabe ao uso de dados somente relacionais. Informações acerca dos pesquisadores como formação, características demográficas e, principalmente, dados que indiquem o acesso a recursos, tipos de habilidades e prestígio no campo científico podem fomentar mais informações sobre quais elementos afetam a formação do capital social em nível individual, assim como servir como variáveis de controle. Tais ações podem aumentar a validade dos mecanismos propostos no estudo. Adicionalmente, nos limitamos às relações de coautoria, em que outros tipos de relações como de amizade e parcerias em projetos podem indicar como elas convergem na produção científica do campo. Ademais, contextos distintos podem ser avaliados, como instituições de ensino e pesquisa, áreas de pesquisa, país, língua, entre muitos outros, já que modelos multiníveis permitem a análise de informações cruzadas entre níveis. Pesquisas que levem em consideração esses pontos podem avançar na explicação do fenômeno da agência imersa, pois possibilitam relacionar tipos distintos de características simultaneamente com a análise de diferentes relações que ocorrem em contextos diversos.

Por fim, só é possível entender as possibilidades e os limites da noção de agência como socialmente imersa e suas implicações no desempenho e na formação de capital social se o mesmo delineamento aqui proposto for avaliado em diferentes tipos de estudos, que envolvam outros tipos de unidades de análise, relações, recursos, contextos, assim como diferentes medidas de avaliação de resultados. Por exemplo, pesquisas devem buscar entender como diferentes relacionamentos interorganizacionais, em contextos culturais e estruturais distintos, afetam medidas de desempenho como inovação, reputação e valor da empresa. Em suma, construir um corpus teórico que explique as implicações da agência como socialmente imersa é um empreendimento que demandará grande número de questões, sendo os elementos apontados anteriormente guias para sua formulação. 


\section{AGENCY AND SMALL WORLDS NETWORKS: \\ A MULTILEVEL ANALYSIS OF ACADEMIC \\ PRODUCTIVITY}

\section{ABSTRACT}

This paper aimed to evaluate empirically the capacity of the agency of researchers in the field of strategy and management research in Brazil while embed in small worlds networks. Therefore, first we evaluated the effect generated by agents in terms of productivity. Then, referring to the structural dimension of context of action, we proposed that, in co-authorship networks, both the privileged position of the researchers in terms of structural holes as the factions of the network configuration in the form of small worlds can be one of the elements that enable the agency. The analysis of how social structure influences the behavior and performance of individuals is primarily based on studies of social network analysis, in that even if acknowledging the limitations, it is as fruitful and coherent methodological framework. However, in parallel, multilevel statistical models have been employed. Commonly knowing as hierarchical linear models or HLM models, they seek to evaluate how context affects social action. Given these two possibilities, this study sought to reconcile the network analysis with hierarchical models to assess the agency as socially immersed in networks of relationships. Thus, the scientific field is taken as a type of social system, whose networks of co-authoring relationships are evaluated as structural dimension in terms of position-practice. That's because there is evidence that the relationship structure interfere both in the process of institutionalization of the shares, as the capacity for agency researchers. We found that the small worlds networks affects the academic productivity both collectively and individually, as well as the presence of structural holes at the individual level. These results point to the importance of assessing the capacity of agency while embed in social networks, since different mechanisms of social capital conditioning the actions.

\section{KEYWORDS}

Agency. Structure. Small worlds networks. Structural holes. Academic productivity. 


\section{AGENCIA Y REDES MUNDOS PEQUEÑOS: UN ANÁLISIS MULTINIVEL DE LA PRODUCTIVIDAD ACADÉMICA}

\section{RESUMEN}

En este artículo, evaluamos empíricamente la capacidad de los investigadores de campo de agencias de organizaciones de investigación y estrategia en Brasil mientras se está inmerso en pequeñas redes de mundos (small worlds). Por lo tanto, se supone que la agencia puede ser evaluada en términos de su efecto sobre la productividad. Luego nos defendemos que tal agencia se puede explicar por la inmersión en las redes de coautoría, en el que tanto la posición privilegiada de los investigadores en cuanto a las brechas estructurales como el establecimiento de redes entre facciones en la forma de pequeños mundos pueden afectar la productividad. El análisis de cómo la estructura social influye en el comportamiento y el rendimiento de las personas se basa principalmente en los estudios de análisis de redes sociales, en los que, aunque reconociendo las limitaciones, es tan fructífera y coherente marco metodológico. Sin embargo, en paralelo, se han empleado modelos estadísticos multinivel. Conocido comúnmente como modelos lineales jerárquicos o modelos HLM, tratan de evaluar cómo el contexto afecta la acción social. Teniendo en cuenta estas dos posibilidades, este estudio trata de conciliar el análisis de red con los modelos jerárquicos para evaluar a la agencia como socialmente inmersa en las redes de relaciones. Por lo tanto, el campo científico se toma como un tipo de sistema social, cuyas redes de relaciones de coautoría son evaluadas como dimensión estructural en términos de posición-práctica. Eso es porque no hay evidencia de que la estructura de la relación interfiere tanto en el proceso de institucionalización de las acciones, como en la capacidad de los investigadores de la agencia. Encontramos que los investigadores con una mayor proporción de los vínculos no redundantes son más productivos. Por otra parte, los análisis mostraron que en las redes más cohesionadas en términos de pequeños mundos, tanto individual como colectivamente, la productividad es mayor. Sin embargo, donde dicha cohesión es demasiado alta, hay una tendencia a que la disminución de la productividad. Estos resultados apuntan a la importancia de evaluar la capacidad de la agencia mientras se está inmerso en las redes de relaciones, ya que los diferentes mecanismos de capital social influyen en la acción y sus resultados. 


\section{palabras clave}

Agencia. Estructura. Redes pequeños mundos. Agujeros estructurales. La productividad académica.

\section{REFERÊNCIAS}

Acedo, F., Barroso, C., Casanueva, C., \& Galán, J. (2006). Co-authorship in management and organizational studies: an empirical and network analysis. Journal of Management Studies, 43(5), 957-983.

Barabasi, A. (2005). Network theory: the emergence of the creative enterprise. Science, 308, 639-64I. Batagelj, V., \& Mrvar, A. (2008). Pajek: Program for analysis and visualization of large networks. Ljubljana: University of Ljubljana.

Becker, H. S. (1982). Art worlds. Berkeley: University of California Press.

Borgatti, S. P. (I997). Structural holes: unpacking burt's redundancy measures. Connections, 20(I), 35-38.

Borgatti, S. P., Everett, M. G., \& Freeman, L. C. (2002). UcinetCINET for Windows: software for social network analysis. Boston: Harvard Analytic Technologies.

Bourdieu, P. (I980). Le capital social: notes provisoires. Actes de La Recherche en Sciences Sociales, 31, 2-3.

Bourdieu, P. (1983). The forms of capital. In J. G. Richardson. Handbook of theory and research for the sociology of education (pp. 24I-258). Westport: Greenwood Press.

Bryk, A. S., \& Raudenbush, S. W. (I992). Hierarquical linear models: applications and data analysis methods. Newbury Park: Sage.

Burgers, W. P., Hill, C. W. L., \& Kim, W. C. (1993). A theory of global strategic alliances: the case of the global auto industry. Strategic Management Journal, 14(6), 419-432.

Burt, R. S. (I980). Models of network structure. Annual Review of Sociology, 6, 79-I4I.

Burt, R. S. (I992). Structural holes: the social structure of competition. Cambridge: Harvard University Press.

Burt, R. S. (2000). The structure of social capital. In: R. Sutton, \& B. M. Staw. Research in organizational behavior (Vol. 22, pp. 345-423). Greenwich: JAI Press.

Burt, R. S. (2002). Bridge decay. Social Networks, 24, 333-363.

Burt, R. S. (2004). Structural holes and good ideas. American Journal of Sociology, 110(2), 349-399. Burt, R. S. (2007). Secondhand brokerage: evidence on the importance of local structure for managers. Bankers, and analysts. Academy of Management Journal, 50(I), II9-I48.

Cohen, I. (I999). Teoria da estruturação e práxis social. In A. Giddens, \& J. Turner (Orgs.). Teoria social hoje (pp 393-446). São Paulo: Editora da Unesp.

Coleman, J. (I988). Social capital in the creation of human capital. American Journal of Sociology, 94(I), S95-Si20.

Coleman, J. (I990). Foundations of social theory. Chicago: University of Chicago Press. 
Davis, G. F., Yoo, M., \& Baker, W. (2003). The small world of the American corporate elite: 1982200I. Strategic Organization, 1(3), 30I-326.

De Nooy, W. (2003). Fields and networks: correspondence analysis and social network analysis in the framework of field theory. Poetics, 31(5-6), 305-327.

De Nooy, W., Mrvar, A., \& Batagelj, V. (2005). Exploratory social network analysis with Pajek. New York: Cambridge University Press.

Diprete, T. A., \& Eirich, G. M. (2006). Cumulative advantage as a mechanism for inequality: a review of theoretical and empirical developments. Annual Review of Sociology, 32, 27I-297.

Emirbayer, M. (I997). Manifesto for a relational sociology. American Journal of Sociology, 103(2), 28I-3I7.

Emirbayer, M., \& Goodwin, J. (I994). Network analysis, culture and the problem of agency. American Journal of Sociology, 99(6), I4II-I454.

Emirbayer, M., \& Mische, A. (I998). What is agency? American Journal of Sociology, 103(4), 962-I023. Flap, H. D. (I99I). Social capital in the reproduction of inequality. Comparative Sociology of Family, Health and Education, 20, 6179-6202.

Fleming, L., \& Marx, M. (2006). Managing creativity in small worlds. California Management Review, 48(4), 6-27.

Freeman, L. C. (I979). Centrality in social networks: I. Conceptual clarification. Social Networks, 1, 215-239.

Friedkin, N. E. (1998). A structural theory of social influence. Cambridge: Cambridge University Press. Fuchs, S. (I993). A sociological theory of scientific change. Social Forces, 71(4), 933-953.

Garud, R., Hardy, C., \& Maguire, S. (2007). Institutional entrepreneurship as embedded agency: an introduction to the special issue. Organization Studies, 28(7), 957-969.

Giddens, A. (1978). Novas regras do método sociológico. Rio de Janeiro: Zahar.

Giddens, A. (1989). A constituição da sociedade. São Paulo: Martins Fontes.

Glover, F. (1989). Tabu search - Part I. Orsa Journal on Computing, 1(3), I90-206.

Glover, F. (I990). Tabu search - Part II. Orsa Journal on Computing, 2(I), 4-32.

Granovetter, M. S. (1973). The strength of weak ties. American Journal of Sociology, 78(6), I36I-1380.

Granovetter, M. S. (1985). Economic action and social structure: the problem of embeddedness. American Journal of Sociology, 91, 48I-5I0.

Goyal, S., Leij, M. J. van der, \& Moraga-González, J. L. (2006). Economics: an emerging small world. Journal of Political Economy, 114(2), 403-4I2.

Guimera, R., Uzzi, B., Spiro, J., \& Amaral, L. A. N. (2005). Team assembly mechanisms determine collaboration network structure and team performance. Science, 308, 697-702.

Hamming, R. W. (I950). Error detecting and error correcting codes. Bell System Techinical Journal, 29(2), I47-160.

Katz, J. S., \& Martin, B. R. (I997). What is research collaboration? Research Policy, 26(I), I-I8.

Kirschbaum, C., \& Vasconcelos. F. C. (2007). Tropicália: manobras estratégicas em redes de músicos. Revista de Administração de Empresas, 43(3), I0-26.

Kogut, B., \& Walker, G. (200I). The small world of Germany and the durability of national networks. American Sociological Review, 66(3), 3I7-335.

Kuhn, T. S. (1978). A estrutura das revoluções científicas (2a ed.). São Paulo: Perspectiva. 
Lazega, E., Jourda, M., Mounier, L., \& Stofer, R. (2008). Catching up with big fish in the big pond? Multi-level network analysis through linked design. Social Networks, 30, I59-I76.

Lazzarini, S. G. (2007a). Mudar tudo para não mudar nada: análise da dinâmica de redes de proprietários no Brasil como "mundos pequenos". RAE-Eletrônica, 6(I).

Lazzarini, S. G. (2007b). The impact of membership in competing alliance constellations: evidence on the operational performance of global. Strategic Management Journal, 28(2), 345-367.

Lee, S., \& Bozeman, B. (2005). The impact of research collaboration on scientific productivity. Social Studies of Science, 35(5), 673-702.

Lin, N. (I982). Social resources and instrumental action. In P. V. Marsden, \& N. Lin. Social structure and network analysis (pp I3I-I45). Beverly Hills: Sage.

Lin, N. (200I). Social capital: a theory of social structure and action. Cambridge: Cambridge University Press.

Lorrain, F., \& White, H. C. (I97I). Structural equivalence of individuals in social networks. Journal of Mathematical Sociology, 1, 49-80.

Luke, D. (2004). Multilevel modeling. Thousand Oaks: Sage.

Machado-da-Silva, C. L., Fonseca, V. S., \& Crubellate, J. M. Estrutura, agência e interpretação: elementos para uma abordagem recursiva do processo de institucionalização. Revista de Administração Contemporânea, 9(ed. especial), 9-39.

Machado-da-Silva, C. L., Guarido Filho, E. R., \& Rossoni, L. (2006). Organizational fields and the structuration perspective: analytical possibilities. Brazilian Administration Review, 3(2), 32-56.

Martins, G. S., Rossoni, R., Csillag, J. M., Martins, M. E., \& Pereira, S. C. F. (20I0). Gestão de operações no Brasil: uma análise do campo científico a partir da rede social de pesquisadores. RAE-Eletrônica, 9(2), art. 8.

Mcphearson, M., Smith-Lovin, L., \& Cook, J. M. (200I). Birds of a feather: homophily in social networks. Annual Review of Sociology, 27, 4I5-444.

Merton, R. K. (I973). The sociology of science. Chicago: University of Chicago Press.

Merton, R. K. (I996). The reward system of science. In R. K. Merton. On social structure and science (pp. 286-303). Chicago: The University of Chicago Press.

Milgram, S. (I967). The small-world problem. Psychology Today, 1(I), 6I-67.

Moody, J. (2004). The structure of a social science collaboration network: disciplinary cohesion from I963 to I999. American Sociological Review, 69(2), 213-238.

Moody, J., \& White, D. R. (2003). Structural cohesion and embeddedness: a hierarchical concept of social groups. American Sociological Review, 68, 103-127.

Newman, M. E. J. (2004). Co-authorship networks and patterns of scientific collaboration. Proceedings of the National Academic Sciences, Washington, DC, USA.

Newman, M. E. J. (200Ia). Scientific collaboration networks. I. Network construction and fundamental results. Physical Review E, 64(I6r3I), I-8.

Newman, M. E. J. (200Ib). Scientific collaboration networks. II. Shortest paths, weighted networks and centrality. Physical Review E, 64(16132), I-7.

Newman, M. E. J. (200Ic). The structure of scientific collaboration networks. Proceedings of the National Academic Sciences, Washington, DC, USA.

Nohria, N., \& Garcia-Pont, C. (I99I). Global strategic alliances and industry structure. Strategic Management Journal, 12(special issue), I05-I24. 
Powell, W. W., White, D. R., Koput, K. W., \& Owen-Smith, J. (2005). Network dynamics and field evolution: the growth of interorganizational collaboration in the life sciences. American Journal of Sociology, 110(4), II32-I205.

Raudenbush, S. W., Bryk, T., \& Congdon, R. (2004). HLM 6: hierarchical linear and nonlinear mo deling. Lincolnwood: Scientific Software International.

Reed, M. (2003). The agency/structure dilemma in organization theory: open doors and brick walls. In H. Tsoukas, \& C. Knudsen (Ed.). The Oxford handbook of organization theory (pp. 289-309). New York: Oxford University Press.

Rossoni, L., \& Guarido Filho, E. R. (2009). Cooperação entre programas de pós-graduação em Administração no Brasil: evidências estruturais em quatro áreas temáticas. Revista de Administração Contemporânea, 13(3), 366-390.

Rossoni, L., Guarido Filho, E. R., \& Machado-da-Silva, C. L. (20I0). A questão da agência em redes acadêmicas de pesquisa: centralidade, produtividade e escolha preferencial. Redes - Revista Hispana para el Análisis de Redes Sociales, 19, 95-I2I.

Rossoni, L., \& Hocayen-da-Silva, A. J. (2008). Cooperação entre pesquisadores da área de administração da informação: evidências estruturais de fragmentação das relações no campo científico. Revista de Administração da USP, 43(2), I38-I5I.

Rossoni, L., \& Machado-da-Silva, C. L. (2008). Análise institucional da construção do conhecimento científico em mundos pequenos. Faces, 7(I), 25-43.

Schilling, M., \& Phelps, C. C. (2007). Interfirm collaboration networks: the impact of large-scale network structure on firm innovation. Management Science, 53(7), III3-II26.

Scott, J. (2000). Social network analysis: a handbook (2a ed.). London: Sage.

Simmel, G. (1950). The sociology of Georg Simmel. New York: Free Press.

Snijders, T. A. B., \& Bosker, R. J. (I999). Multilevel analysis: an introduction to basic and advanced multilevel modeling. London: Sage.

Uzzi, B. (I996). The sources and consequences of embeddedness for economic performance of organizations: the network effect. American Sociological Review, 61(4), 674-698.

Uzzi, B., Amaral, L. A. N., \& Reed-Tsochas, F. (2007). Small-world networks and management science research: a review. European Management Review, 4, 77-9I.

Uzzi, B., \& Spiro, J. (2005). Collaboration and creativity: the small world problem. American Journal of Sociology, 111(2), 447-504.

Vanhaverbeke, W., \& Noorderhaven, N. G. (200I). Competition between alliance blocks: the case of the Risc microprocessor technology. Organization Studies, 222(I), I-30.

Wagner, C. S., \& Leydesdorff, L. (2005). Network structure, self-organization, and the growth of international collaboration in science. Research Policy, 34(10), 1608-1618.

Wasserman, S., \& Faust, K. (I994). Social network analysis: methods and applications. Cambridge: Cambridge University Press.

Watts, D. J. (I999a). Networks, dynamics, and small-world phenomenon. American Journal of Sociology, 105(2), 493-527.

Watts, D. J. (I999b). Small worlds: the dynamics of networks between order and randomness. Princeton: Princeton University Press.

Watts, D. J. (2004). The "new" science of networks. Annual Review of Sociology, 30, 243-270. 
Watts, D. J., \& Strogatz, S. H. (I998). Collective dynamics of "small-world" networks. Nature, 393, 440-442.

White, H. C. (I992). Identity and control: a structural theory of social action. Princeton: Princeton University Press.

White, D. R., Owen-Smith, J., Moody, J., \& Powell, W. W. (2004). Networks, fields and organizations: micro-dynamics, scale and cohesive embeddings. Computational \& Mathematical Organization Theory, 10(I), 95-II7.

Wuchty, S., Jones, B. F., \& Uzzi, B. (2007). The increasing dominance of teams in production of knowledge. Science, 316, го36-1039. 